\title{
Um relato de ensino de Química no contexto da pandemia de COVID-19 na rede pública de São Paulo: O desafio das aulas virtuais na Educação Básica
}

\author{
A report of teaching chemistry in the context of the pandemic of COVID-19 in the public network \\ of São Paulo: The challenge of virtual classes in Basic Education \\ Un informe de la enseñanza de la química en el contexto de la pandemia de COVID-19 en la red \\ pública de São Paulo: El desafío de las clases virtuales en Educación Básica
}

Recebido:22/01/2021 | Revisado: 24/01/2021 | Aceito: 28/01/2021 | Publicado: 05/02/2021

Jefferson Rodrigo dos Santos

ORCID: https://orcid.org/0000-0002-9849-8008 Instituto Federal de Educação, Ciência e Tecnologia de Minas Gerais, Brasil E-mail: jotars02@gmail.com

Maria Elisa Ferreira

ORCID: https://orcid.org/0000-0003-2404-5433 Instituto Federal de Educação, Ciência e Tecnologia de Minas Gerais, Brasil E-mail: mariaelisasimpson@gmail.com

\begin{abstract}
Resumo
Este artigo apresenta reflexões acerca da utilização de aulas virtuais como estratégia para garantir aos estudantes da Educação Básica, no ensino público, a continuidade da aprendizagem no contexto da pandemia de COVID-19. Pretendeu-se compreender os impactos imediatos do ensino remoto por meio de ferramentas digitais. Considerando características específicas da rede estadual de ensino do Estado de São Paulo, bem como os recursos disponibilizados para estudantes e docentes, a partir de relato de prática, foram analisadas estratégias didáticas com utilização de ferramentas digitais para ensino de Química em turmas do Ensino Médio. Assim, foi adotada a abordagem qualitativa, considerando os registros da plataforma Google Classroom, além de pesquisa bibliográfica. O estudo revelou o empenho da Secretaria da Educação do Estado de São Paulo em viabilizar o ensino remoto, assim como o esforço e dificuldades enfrentadas por docentes e estudantes, principalmente quanto ao acesso digital. Ademais, observou-se a adoção de estratégias incomuns no contexto escolar, como a utilização de redes sociais e aplicativos de comunicação. Concluiu-se que a utilização de ferramentas digitais de ensino e aprendizagem na Educação Básica tem aspectos positivos, como possibilitar novas maneiras de ensinar e aprender, favorecendo o uso de diferentes linguagens e a autonomia dos estudantes. $\mathrm{O}$ estudo sugere que as estratégias adotadas se mostraram adequadas às necessidades emergenciais do ensino remoto, entretanto, as análises não possibilitam mensurar as implicações na efetiva aprendizagem, aspecto que poderá motivar outros trabalhos.
\end{abstract}

Palavras-chave: Ensino; Ensino-aprendizagem; Ferramentas digitais; Química.

\begin{abstract}
This paper presents reflections on the use of virtual classes as a strategy to guarantee students of Basic Education, in public education, the continuity of learning in the context of the pandemic of COVID-19. It was intended to understand the immediate impacts of remote education through digital tools. Considering specific characteristics of the state education network of the State of São Paulo, as well as the resources made available to students and teachers, based on practical reports, didactic strategies were analyzed using digital tools for teaching chemistry in high school classes. Thus, the qualitative approach was adopted, considering the records of the Google Classroom platform, in addition to bibliographic research. The study revealed the efforts of the São Paulo State Department of Education to make remote teaching possible, as well as the effort and difficulties faced by teachers and students, especially regarding digital access. Furthermore, it was observed the adoption of unusual strategies in the school context, such as the use of social networks and communication applications. It was concluded that the use of digital teaching and learning tools in Basic Education has positive aspects, such as enabling new ways of teaching and learning, favoring the use of different languages and students' autonomy. The study suggests that the strategies adopted proved to be adequate to the emergency needs of remote education, however, the analyzes do not allow measuring the implications for effective learning, an aspect that may motivate other works.
\end{abstract}

Keywords: Teaching; Teaching-learning; Digital tools; Chemistry. 


\begin{abstract}
Resumen
Este artículo presenta reflexiones sobre el uso de las clases virtuales como estrategia para garantizar a los estudiantes de Educación Básica, en la educación pública, la continuidad del aprendizaje en el contexto de la pandemia de COVID19. Se pretendía comprender los impactos inmediatos de la educación remota a través de herramientas digitales. Teniendo en cuenta las características específicas de la red educativa estatal del Estado de São Paulo, así como los recursos puestos a disposición de estudiantes y docentes, con base en informes prácticos, se analizaron estrategias didácticas utilizando herramientas digitales para la enseñanza de la química en las clases de secundaria. Así, se adoptó el enfoque cualitativo, considerando los registros de la plataforma Google Classroom, además de la investigación bibliográfica. El estudio reveló los esfuerzos de la Secretaría de Educación del Estado de São Paulo para hacer posible la enseñanza a distancia, así como el esfuerzo y las dificultades que enfrentan los docentes y estudiantes, especialmente en el acceso digital. Además, se observó la adopción de estrategias inusuales en el contexto escolar, como el uso de redes sociales y aplicaciones de comunicación. Se concluyó que el uso de herramientas digitales de enseñanza y aprendizaje en Educación Básica tiene aspectos positivos, como posibilitar nuevas formas de enseñar y aprender, favorecer el uso de diferentes idiomas y la autonomía de los estudiantes. El estudio sugiere que las estrategias adoptadas resultaron adecuadas a las necesidades de emergencia de la educación a distância, sin embargo, los análisis no permiten medir las implicaciones para el aprendizaje efectivo, aspecto que puede motivar otros trabajos.
\end{abstract}

Palabras clave: Ensenãnza; Enseñanza-aprendizaje; Herramientas digitales; Química.

\title{
1. Introdução
}

Em razão da pandemia de COVID-19, o Governo do Estado de São Paulo, considerando o artigo 23 da Lei de Diretrizes e Bases da Educação Nacional (LDB) que, em seu $\S 2^{\circ}$, dispõe sobre a adequação do calendário escolar às peculiaridades locais, inclusive climáticas e econômicas, a critério do respectivo sistema de ensino (Brasil, 1996), determinou a suspensão das aulas presenciais em toda a rede estadual, através do Decreto nº 64862, de 13 de março de 2020 (São Paulo, 2020a), adotando emergencialmente o ensino remoto (São Paulo, 2020e) com a utilização de ferramentas digitais.

Diversas plataformas digitais foram disponibilizadas para uso gratuito pelos estudantes da rede estadual de São Paulo. [...]. Será essencial que os professores analisem antes as plataformas, analisando a adequação do conteúdo e o alinhamento das habilidades do currículo trabalhadas com seus estudantes (São Paulo, 2020d, p.21).

Assim, delineou-se o desafio docente que motivou este trabalho: ensinar Química através de aulas virtuais, o que impôs aos docentes uma postura aprendente, considerando que "quem ensina aprende ao ensinar e quem aprende ensina ao aprender”, como defende Freire (1996, p.17). Nessa perspectiva, a prática docente que será apresentada reflete um processo de ação e reflexão; de ensinar e aprender simultaneamente.

Nesse sentido, Moran (2006, p. 61), defende que: "É importante conectar sempre o ensino com a vida do aluno. Chegar ao aluno por todos os caminhos possíveis", uma vez que: "Na sociedade da informação, todos estamos reaprendendo a conhecer, a nos comunicarmos, a ensinar; reaprendendo a integrar o humano e o tecnológico; a integrar o individual, o grupal e o social".

É importante ressaltar que o ensino remoto foi adotado por grande parte das redes de ensino do país, levando ao estabelecimento de diretrizes no âmbito da educação nacional, como a Medida Provisória no 934/2020, que flexibilizou excepcionalmente a exigência do cumprimento do calendário escolar (Brasil, 2020d).

Art. $1^{\circ} \mathrm{O}$ estabelecimento de ensino de educação básica fica dispensado, em caráter excepcional, da obrigatoriedade de observância ao mínimo de dias de efetivo trabalho escolar, nos termos do disposto no inciso I do caput e no $\S 1^{\circ}$ do art. 24 e no inciso II do caput do art. 31 da Lei $n^{\circ}$ 9.394, de 20 de dezembro de 1996, desde que cumprida a carga horária mínima anual estabelecida nos referidos dispositivos, observadas as normas a serem editadas pelos respectivos sistemas de ensino (Brasil, 2020d, Art. $1^{\circ}$ ).

Considerando esse cenário, o Conselho Nacional de Educação editou o Parecer 05/2020, estabelecendo "orientações com vistas à reorganização do calendário escolar e à possibilidade de cômputo de atividades não presenciais, para fins de cumprimento da carga horária mínima anual, em razão da pandemia do novo coronavírus - COVID-19” (Brasil, 2020a). 
Na rede estadual de ensino de São Paulo, foram adotadas como principais ferramentas: Centro de Mídias da Educação de São Paulo - aplicativo e TV (CMSP), plataforma digital Google Classroom e aplicativos Google, trazendo novas atribuições ao trabalho docente, como aquisição imediata de habilidades para o uso das ferramentas digitais, elaboração e execução de aulas virtuais, além da interação com os estudantes por meio digital.

Essa realidade evidenciou a necessidade de reflexão sobre os impactos no processo de ensino e aprendizagem. Considerando o escopo da pesquisa, destacam-se algumas questões: $\mathrm{O}$ uso de ferramentas digitais, adotadas na rede pública estadual de São Paulo, no contexto em questão, garantem aos estudantes a continuidade da aprendizagem? As plataformas e aplicativos adotados favorecem o ensino de Química? Quais são as principais dificuldades enfrentadas por estudantes e docentes envolvidos no contexto estudado?

Fazendo um recorte da rede estadual de ensino de São Paulo, adotou-se como referência o trabalho desenvolvido por dois docentes em turmas de primeiro e segundo ano do Ensino Médio de uma escola da periferia da cidade de São Paulo e do primeiro ao terceiro ano de duas escolas, também periféricas, da cidade de São Bernardo do Campo. A partir de registros realizados pelos docentes e estudantes na plataforma digital Google Classroom, além de aspectos referentes ao uso do aplicativo Centro de Mídias da Educação de São Paulo, foram analisados os principais impactos imediatos do ensino remoto com utilização de ferramentas digitais para ensino de Química.

\section{Metodologia da Pesquisa}

Neste estudo foi adotada a abordagem qualitativa, na perspectiva de que as reflexões dos pesquisadores são parte do processo de produção do conhecimento, conforme defendido por Flick (2009); Pereira A.S. et al. (2018).

Considerando que o estudo qualitativo supõe a presença dos pesquisadores na situação investigada, assim como as perspectivas dos sujeitos envolvidos (Ludke \& André, M, 2013), realizou-se uma pesquisa exploratória (Köche, 2011), visando à compreensão dos impactos imediatos do ensino remoto, cujos resultados poderão suscitar estudos posteriores (Gil, 2019). Assim, tomando como referência o trabalho desenvolvido por dois docentes de Química, que atuam no Ensino Médio da rede estadual de ensino de São Paulo, foram coletadas informações da plataforma digital Google Classroom, publicadas no período de maio a novembro de 2020, com orientações e atividades propostas pelos docentes, respectivas devolutivas dos estudantes, bem como diálogos via chat da plataforma ou e-mail institucional.

Para a análise do aplicativo CMSP, ferramenta adotada pela rede estadual de ensino de São Paulo, foi realizada coleta de informações disponibilizadas publicamente nas redes sociais oficiais Facebook e Instagram, assim como registros realizados pelos docentes e estudantes na plataforma digital envolvendo o uso do aplicativo. Essa coleta possibilitou também reflexões acerca do uso das redes sociais e aplicativos de comunicação no contexto estudado.

A necessária fundamentação teórica foi viabilizada por pesquisa bibliográfica (Köche, 2011).

\section{Resultados e Discussão}

A partir das informações coletadas, foram analisados aspectos referentes ao uso, por docentes e estudantes, da plataforma digital Google Classroom, de aplicativos Google, do aplicativo Centro de Mídias da Educação de São Paulo, além de ferramentas digitais complementares. De modo geral, esses recursos mostraram-se adequados para o ensino remoto no contexto estudado.

Foi possível observar o empenho da rede de ensino e dos docentes em manter o diálogo com os estudantes e motiválos para a realização das atividades propostas. Nesse sentido foi adotado o uso de aplicativos de comunicação e redes sociais, das quais foram analisadas informações disponibilizadas nas páginas oficiais do CMSP no Instagram e no Facebook. 
Nas atividades propostas pelos docentes, através da plataforma digital, foi possível observar a utilização de recursos interativos a fim de estimular o interesse dos estudantes. Os docentes empenharam-se em orientar, elucidar dúvidas e realizar as devidas devolutivas. Também foi possível perceber o esforço dos estudantes em participar das atividades.

Por outro lado, foi possível observar que tanto docentes quanto estudantes encontraram dificuldades em decorrência da inadequação de redes de internet e dos dispositivos pessoais para as aulas remotas. Além disso, parte dos estudantes não acessou as atividades disponibilizadas na plataforma digital, suscitando reflexões acerca da exclusão digital.

\subsection{O ensino de Química na rede estadual de São Paulo}

Fundamentado na Base Nacional Comum Curricular (BNCC) e no Currículo Paulista, o ensino de Química na rede estadual de São Paulo ocorre desde as etapas iniciais da Educação Básica, no conjunto das Ciências da Natureza, passando para uma abordagem específica no Ensino Médio.

A concepção de ensino de Ciências da Natureza e suas tecnologias, adotada pelo Currículo Paulista, considera a importância do conhecimento científico e tecnológico na constituição da sociedade contemporânea, exigindo o desenvolvimento de habilidades e conhecimentos que favoreçam o letramento científico, a investigação científica, visando à formação de "um sujeito transformador do seu meio, que reflita, proponha, argumente e aja com base em fundamentos científicos e tecnológicos, de modo intencional e consciente, em todos os âmbitos da vida humana" (São Paulo, 2020f, p. 385). Nessa perspectiva, o ensino de Ciências da Natureza inicia-se na Educação Infantil, passando pelo Ensino Fundamental como parte das Ciências da Natureza, numa abordagem interdisciplinar, avançando para o Ensino Médio com a possibilidade de aprofundamento de conhecimentos específicos, considerando a contextualização histórica, social e cultural do conhecimento científico.

A concepção adotada pressupõe a formação integral do indivíduo, assim, o trabalho docente deve centrar-se no estudante, favorecendo seu protagonismo, como previsto no Currículo Paulista.

Ensinar e aprender Ciências na contemporaneidade implica considerar os diversos processos de transformação dos fenômenos naturais e os decorrentes da ação humana, ao longo do tempo, aprimorar e ampliar as habilidades/conhecimentos dos estudantes, mobilizando-as para o enfrentamento adequado desse contexto em transformação (São Paulo, 2020f, p 375).

No Ensino Médio, a disciplina de Química, dialogando com as demais Ciências da Natureza, apresenta um aprofundamento no pensamento e na linguagem científica, considerando que, segundo a Base Comum Nacional Curricular, "a dimensão investigativa das Ciências da Natureza deve ser enfatizada no Ensino Médio, aproximando os estudantes dos procedimentos e instrumentos de investigação" (Brasil, 2018 p. 550).

\subsection{Breve histórico da pandemia de COVID-19}

O dia 31 de dezembro de 2019 tornou-se marco inicial de uma crise sanitária global. Na ocasião, a Organização Mundial da Saúde (OMS) foi alertada sobre diversos casos de pneumonia na cidade de Wuhan, província de Hubei, na República Popular da China (OPAS, 2020a).

No dia 7 de janeiro de 2020, autoridades chinesas divulgaram a identificação de um novo tipo de coronavírus, responsável pela doença COVID 19.

Ao todo, sete coronavírus humanos (HCoVs) já foram identificados: HCoV-229E, HCoV-OC43, HCoV-NL63, HCoV-HKU1, SARS-COV (que causa síndrome respiratória aguda grave), MERS-COV (que causa síndrome respiratória do Oriente Médio) e o, mais recente, novo coronavírus (que no início foi temporariamente nomeado 2019- 
nCoV e, em 11 de fevereiro de 2020, recebeu o nome de SARS-CoV-2). Esse novo coronavírus é responsável por causar a doença COVID-19 (OPAS, 2020a).

O aumento do número de casos da doença na China, e posteriormente em outros países, levou a OMS a declarar o surto de Covid-19 como "Emergência de Saúde Pública de Importância Internacional", a partir de 30 de janeiro de 2020, evoluindo para a classificação de pandemia em 11 de março de 2020 (OPAS, 2020a).

Em janeiro, o novo coronavírus (SARS-CoV-2) estava concentrado na China, e só alguns casos chegavam a outros países, através de pessoas infectadas que viajaram de avião ou navio. No final daquele mês, já eram 10.000 infectados na China e em outros 129 países. Mas em fevereiro foram registrados vários surtos na Coreia do Sul, Itália, Alemanha e Espanha. No Brasil, o primeiro caso foi confirmado em 26 de fevereiro, mas os casos confirmados passavam de 1.500 menos de um mês depois (El País, 2020).

Desde então, a OMS passou a recomendar o isolamento social como estratégia para conter a propagação da doença e evitar o colapso nos sistemas de saúde. Algumas medidas de prevenção individual também foram recomendadas, como usar máscara, "manter uma distância física mínima de pelo menos um metro de outras pessoas, limpar frequentemente as mãos e evitar tocar no rosto e na máscara" (OPAS, 2020b).

Diante das recomendações da OMS, autoridades de vários países adotaram medidas sanitárias, que incluíram desde o fechamento de serviços não essenciais, isolamento social, até lockdown. Segundo a Fundação Oswaldo Cruz (Brasil, 2020g), apesar de causar impactos econômicos, "o isolamento social é essencial para evitar um aumento desenfreado da doença e o colapso no sistema de saúde"; o lockdown pode ser adotado para "conter de forma mais rápida e eficaz a disseminação do vírus".

No Brasil, a Portaria no 188, de 3 de fevereiro de 2020, editada pelo Ministério da Saúde, declarou "Emergência em Saúde Pública de Importância Nacional, em razão da infecção humana pelo novo Coronavírus (COVID-19)”. Além disso, entrou em vigor a Lei Federal n 13.979 , de 06 de fevereiro de 2020, que estabelece regras para enfrentamento da pandemia. Em 20 de março de 2020, o Congresso Nacional aprovou o Decreto Legislativo $\mathrm{n}^{\circ}$ 6, reconhecendo o "estado de calamidade pública" (Brasil, 2020e; Brasil, 2020c; Brasil, 2020b).

$\mathrm{O}$ avanço da pandemia no país ocorreu rapidamente, fazendo com que governadores e prefeitos, seguindo orientações da OMS, adotassem medidas restritivas. Assim, o Governo do Estado de São Paulo, por meio do Decreto n ${ }^{\circ} 64.862$, de 13 de março de 2020 (São Paulo, 2020a), determinou "medidas temporárias e emergenciais de prevenção de contágio pelo COVID19", reconhecendo, por meio do Decreto $\mathrm{n}^{\mathrm{0}}$ 64879, de 20/03/2020, estado de calamidade pública (São Paulo, 2020b) e determinando quarentena, por meio do Decreto nº 64.881, de 22 de março de 2020 (São Paulo, 2020c).

Em decorrência da pandemia, impactos econômicos, políticos e sociais ocorrem em escala global, atingindo também a educação. Nesse panorama, as aulas presenciais foram suspensas e o ensino remoto por meio de ferramentas digitais foi adotado por diversas redes de ensino, inclusive a rede estadual de São Paulo, cujo trabalho docente tem um recorte abordado neste trabalho.

\subsection{Aulas virtuais no contexto da pandemia de COVID-19}

Até o início do ano letivo de 2020, ferramentas digitais de ensino e aprendizagem não faziam parte dos recursos regulares da rede estadual de ensino de São Paulo, entretanto, com a suspensão das aulas presenciais e adoção emergencial do ensino remoto em decorrência da pandemia de COVID-19, algumas ferramentas foram adotadas, estabelecendo um cenário bem diverso do habitual. 
Para os docentes, o primeiro desafio foi a aquisição de conhecimentos acerca das ferramentas digitais adotadas. Outra questão relevante foi a inadequação dos recursos utilizados, compostos geralmente por redes de internet e dispositivos pessoais.

A fim de viabilizar o ensino remoto, a Secretaria Estadual de Educação de São Paulo adotou o Centro de Mídias da Educação de São Paulo - aplicativo e TV (CMSP), disponível para download em dispositivos compatíveis com os sistemas Android e iOS, com utilização sem consumo de dados móveis de internet. Nesse aplicativo são transmitidos vídeos por série/ano da Educação Básica, assim como aulas online. As transmissões podem ser acompanhadas "pelo site do Centro de Mídias SP, pelo aplicativo CMSP, pela página no Facebook e, ainda, pelos canais da TV aberta: TV Educação e TV Univesp" (São Paulo, 2020b, p.19). O CMSP também disponibiliza no YouTube as aulas gravadas, além de possibilitar acesso à plataforma digital Google Classroom e aplicativos Google.

Após as orientações iniciais, o CMSP passou a ser utilizado, tanto para o ensino remoto, quanto para encontros formativos dos docentes e gestores. Além das discussões habituais sobre questões pedagógicas e orientações institucionais, esse espaço formativo também foi utilizado para a troca de informações sobre a funcionalidade das ferramentas digitais.

É importante ressaltar a relevância da iniciativa da Secretaria da Educação do Estado de São Paulo, no sentido de garantir a continuidade das aulas por meio do CMSP, cuja utilização não consome dados móveis de internet, além de possibilitar a interação entre docentes e estudantes por meio de chat ou videoconferência, assim como o acesso aos canais de conteúdo e à plataforma Google Classroom, entretanto, evidenciam-se alguns obstáculos na sua utilização, como discrepâncias relatadas por estudantes, necessidade de dispositivo adequado, compatível com os sistemas Android e iOS, além de acesso digital inicial para download do aplicativo.

Para garantir o diálogo entre educadores, estudantes e suas famílias, foram adotados canais de comunicação geralmente pouco utilizados no ensino presencial, como mensagens por aplicativos e redes sociais. 
Research, Society and Development, v. 10, n. 2, e8710212267, 2021

(CC BY 4.0) | ISSN 2525-3409 | DOI: http://dx.doi.org/10.33448/rsd-v10i2.12267

Figura 1. Página oficial do CMSP no Instagram.

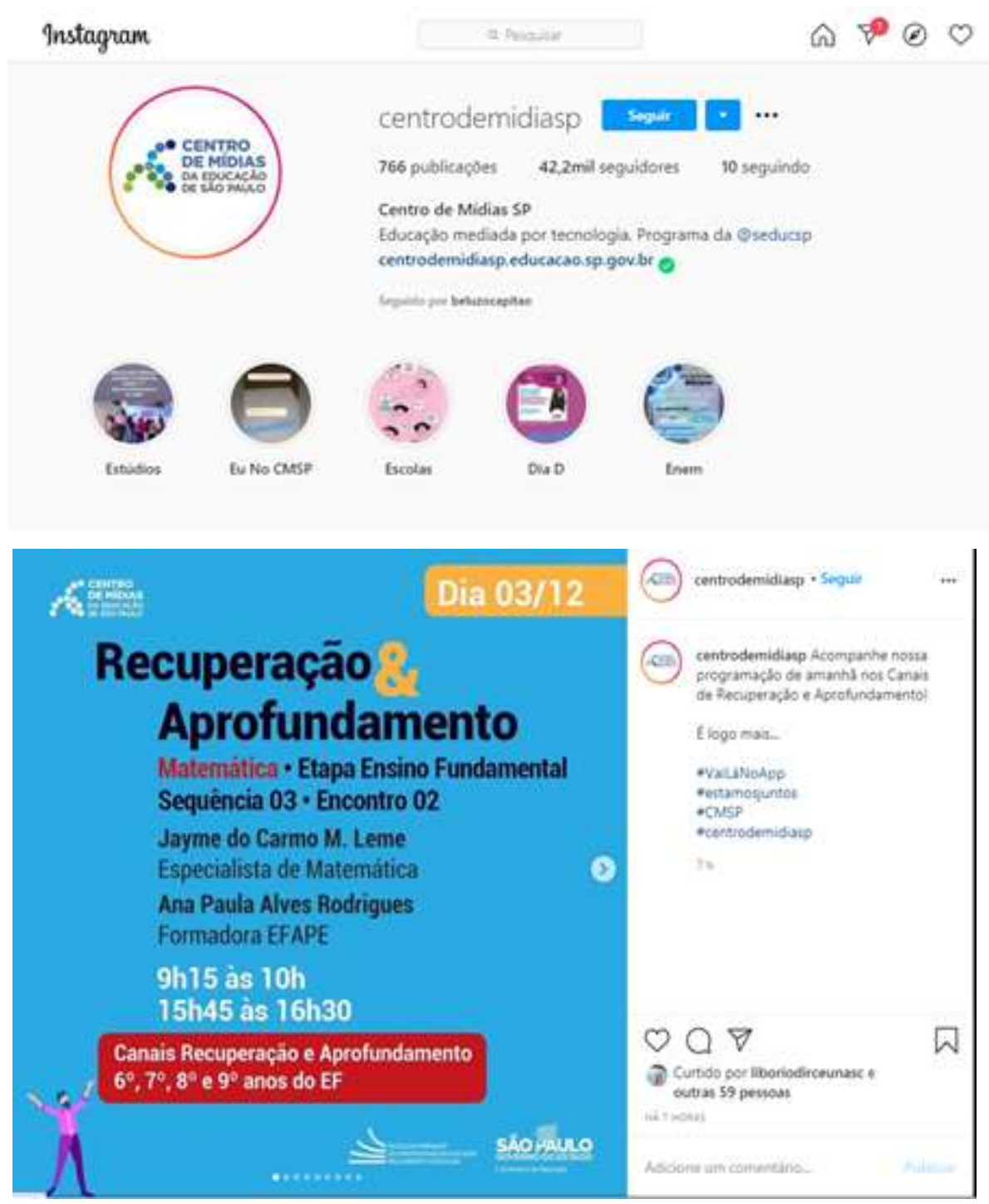

Fonte: Instagram.

A Figura 1 refere-se à página do CMSP no Instagram, na qual foram publicadas informações sobre conteúdos disponibilizados pela Secretaria da Educação do Estado de São Paulo no aplicativo. 
Figura 2. Página oficial do CMSP no Facebook.

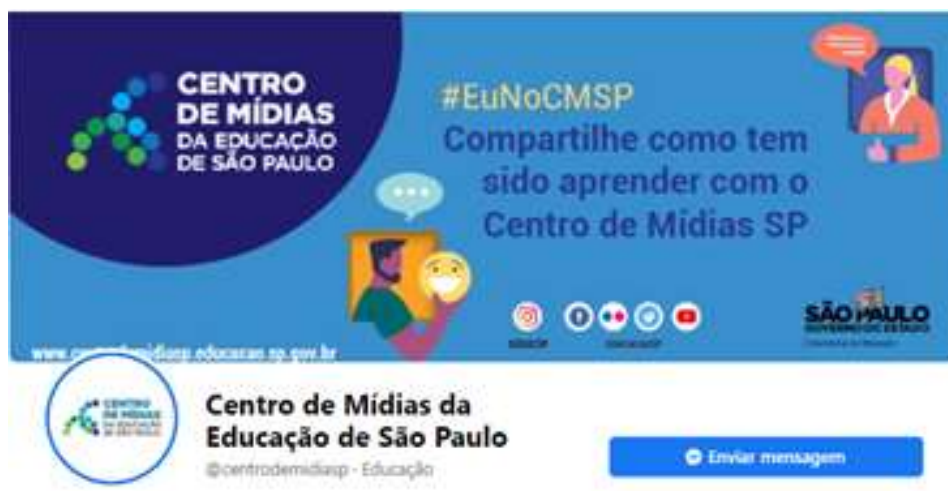

Centro de Midias da Educação de Sào Paulo 26 de novembro ás 07:00.69

Temos um recadinho para os alunos, pais e responsáveis! Aproveitamos para agradecer quem acompanha nossas aulas pelo App e pela TV.

Continue com a gentel:!

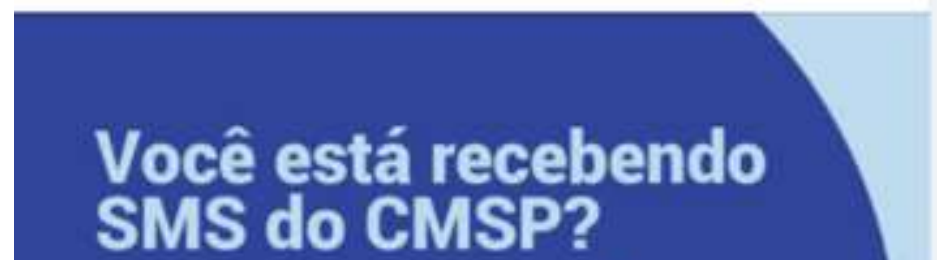

Essas mensagens são apenas para quem está com as atividades incompletas e não tem acompanhado as aulas. Se nāo é o seu caso, fica tranquilo! Continue com a gente e garanta a continuidade dos seus estudos.

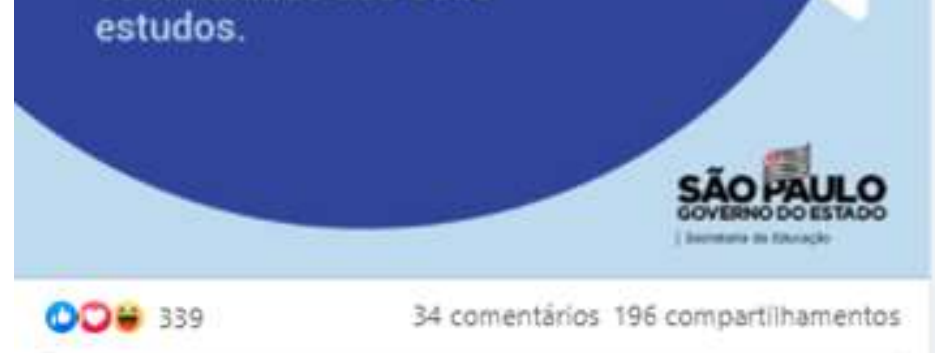

Fonte: Facebook.

A Figura 2 refere-se à página do CMSP no Facebook, evidenciando o empenho da Secretaria da Educação do Estado de São Paulo em manter os estudantes informados e motivados a acessar os conteúdos disponibilizados no CMSP.

Nas páginas oficiais do CMSP no Instagram e no Facebook também é possível observar comentários de diversos atores do contexto escolar, apontando aspectos positivos e negativos sobre o uso do aplicativo, como indicam as Figuras 3 e 4. 
Research, Society and Development, v. 10, n. 2, e8710212267, 2021

(CC BY 4.0) | ISSN 2525-3409 | DOI: http://dx.doi.org/10.33448/rsd-v10i2.12267

Figura 3. Página oficial do CMSP no Facebook.

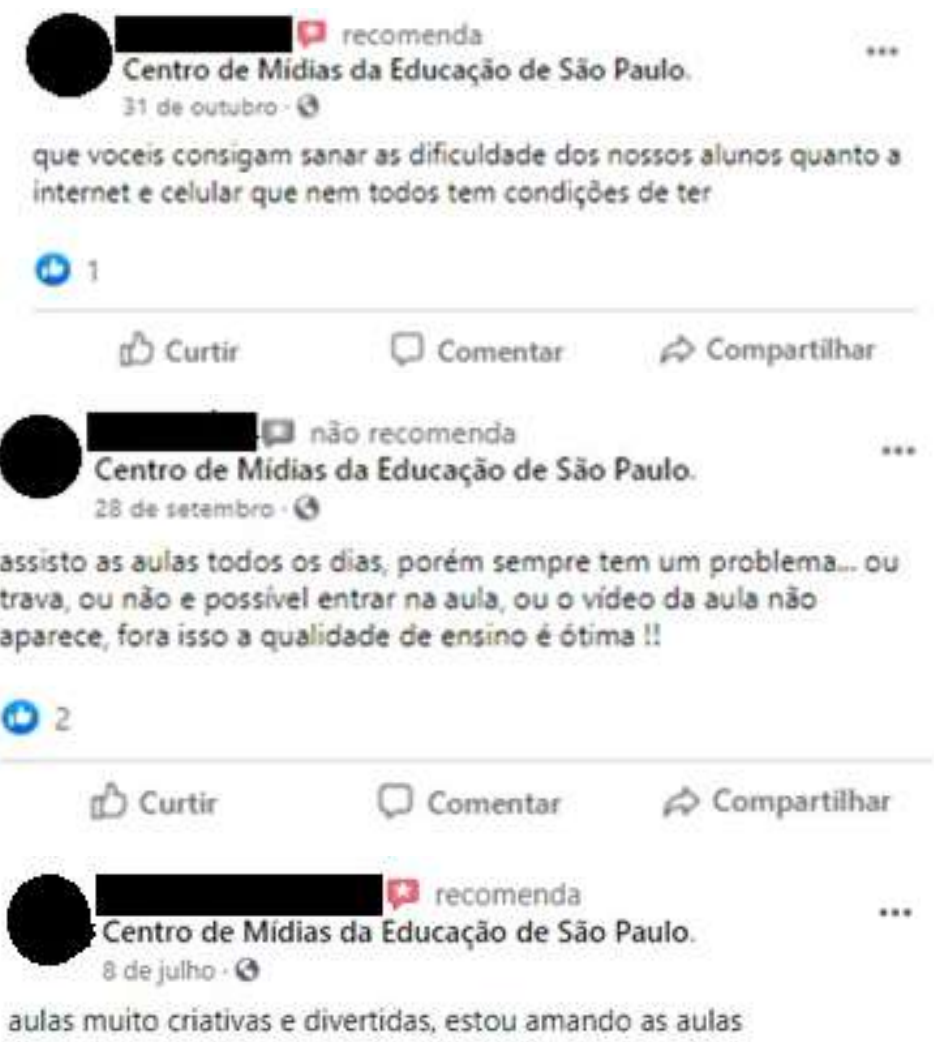

aulas muito criativas e divertidas, estou amando as aulas

Qё 5

1 comentărio

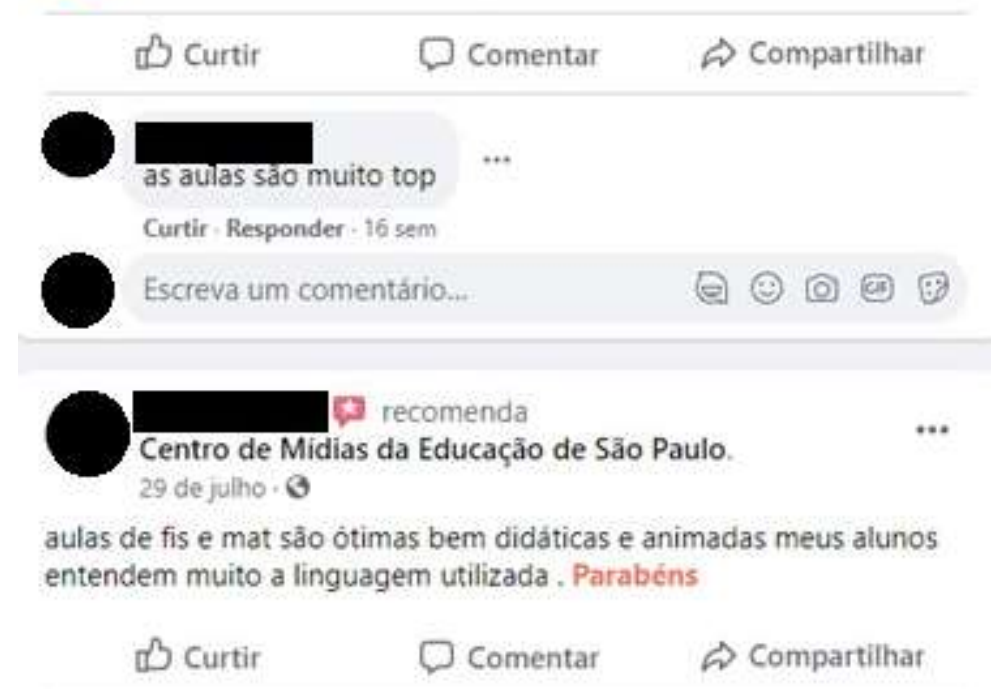

Fonte: Facebook.

A Figura 3 apresenta comentários postados no Facebook, com críticas e elogios ao CMSP, exemplificando as percepções de pais, estudantes e docentes. 
Figura 4. Página oficial do CMSP no Facebook.

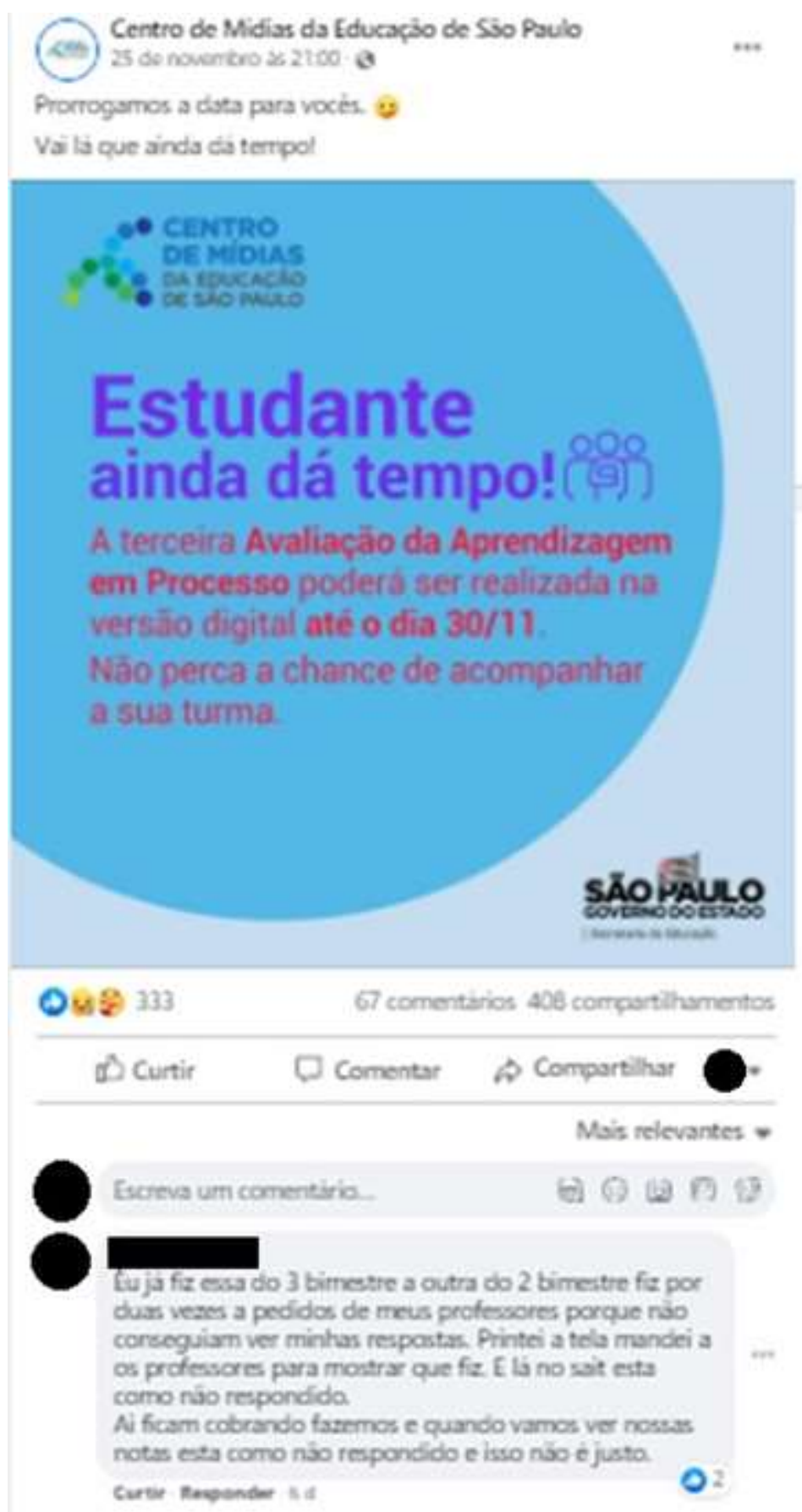

Fonte: Facebook.

Na Figura 4, observa-se um comentário de estudante, postado no Facebook, apontando falhas do CMSP quanto ao registro das atividades realizadas.

Embora tradicionalmente o protocolo pedagógico não inclua o uso das redes sociais e aplicativos de comunicação, no contexto da pandemia de COVID-19, esse uso foi adotado por diversas instituições e por docentes como estratégia para manter o diálogo com os estudantes e suas famílias, a fim de estimular e orientar a continuidade dos estudos. Representando uma quebra de paradigma, cujas consequências poderão ser analisadas no contexto de pós-pandemia, tal iniciativa encontra respaldo no Parecer n $\mathrm{n}^{\circ}$ 15/2020 do CNE, que "estabelece normas educacionais excepcionais a serem adotadas pelos sistemas de ensino, instituições e redes escolares, públicas, privadas, comunitárias e confessionais, durante o estado de calamidade reconhecido 
pelo Decreto Legislativo $\mathrm{n}^{\circ}$ 6, de 20 de março de 2020." A respeito das referidas ferramentas, no Artigo 11, IV, o Parecer $\mathrm{n}^{\circ}$ 15/2020 do CNE afirma que "cabe às secretarias de educação e a todas as instituições escolares: [...] utilizar mídias sociais de longo alcance (WhatsApp, Facebook, Instagram etc.) para estimular e orientar os estudos, pesquisas e projetos que podem ser computados no calendário e integrar o replanejamento curricular" (Brasil, 2020f).

A despeito dos esforços dos docentes e das instituições na divulgação de informações sobre as aulas remotas, evidenciam-se alguns obstáculos à participação dos estudantes nas atividades. O primeiro, e talvez mais relevante, diz respeito ao acesso digital.

Figura 5. Gráfico de acesso dos estudantes às aulas virtuais.

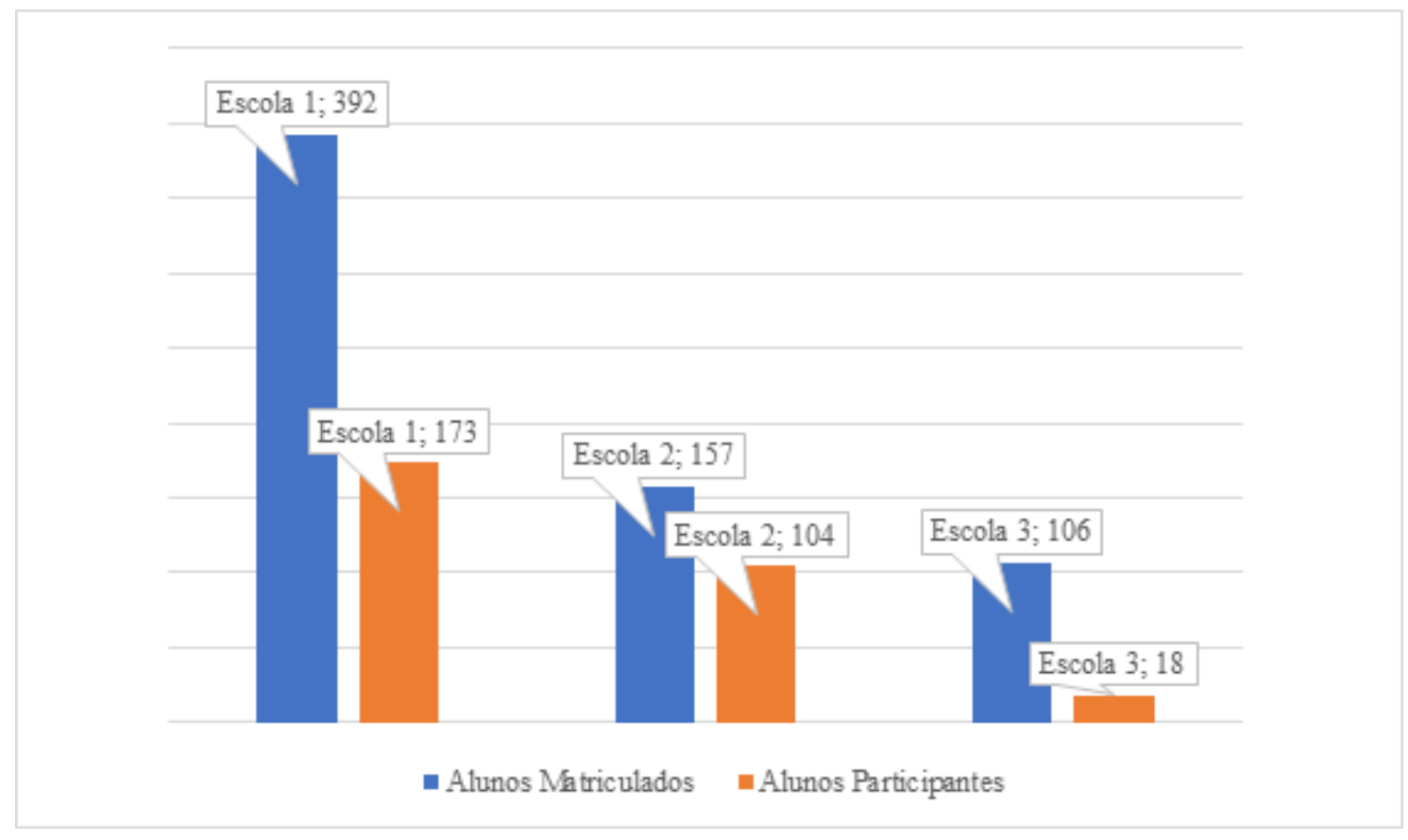

Fonte: Autores.

A Figura 5 apresenta gráfico, elaborado a partir de dados coletados da plataforma Google Classroom, sobre o acesso dos estudantes às aulas virtuais, evidenciando que o alcance foi parcial.

Este estudo não possibilita enumerar todos os obstáculos ao acesso dos estudantes às aulas virtuais, entretanto, considerando que todos os recursos de comunicação disponíveis foram utilizados (mensagens por e-mail, grupos de WhatsApp, Facebook), é possível inferir algum grau de exclusão digital decorrente da falta de rede de internet e dispositivos adequados, como indicam as Figuras 6 e 7.

Figura 6. Google Classroom - Chat.

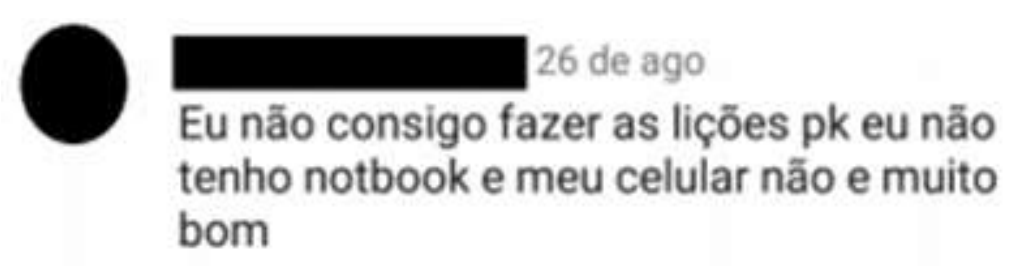

Fonte: Google Classroom. 
A Figura 6 revela dificuldade de estudante em realizar atividades devido à inadequação de dispositivo.

Figura 7. Google Classroom-Chat.

\section{Comentários da turma}

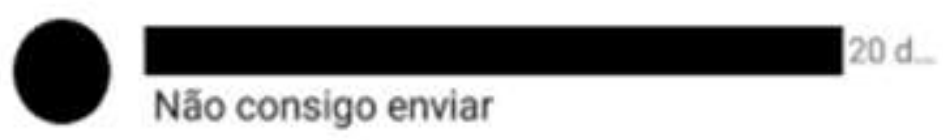

\section{Fonte: Google Classroom.}

A Figura 7 indica dificuldade de estudante em enviar atividade devido à possível inadequação da rede de internet disponível.

Além de questões referentes ao acesso digital, evidenciaram-se outros obstáculos enfrentados por parte dos estudantes, como pode ser observado nas Figuras 8 e 9.

Figura 8. Google Classroom - Chat.

\section{Comentários da turma}

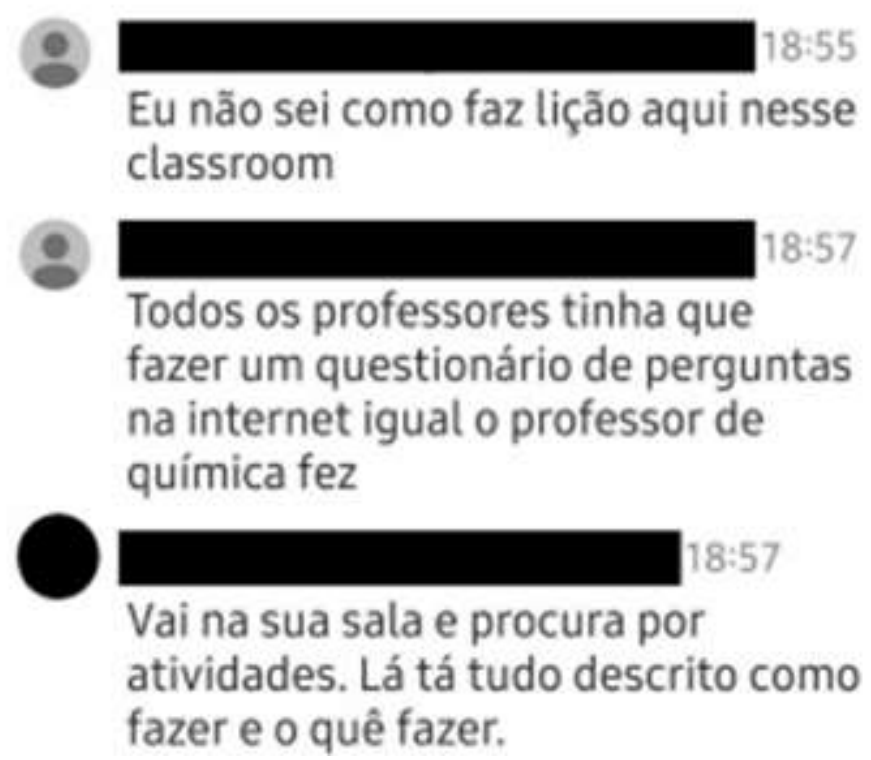

Fonte: Google Classroom.

A Figura 8 apresenta diálogo da turma, revelando dificuldade de estudante em utilizar a plataforma digital para realização de atividade proposta. 
Research, Society and Development, v. 10, n. 2, e8710212267, 2021

(CC BY 4.0) | ISSN 2525-3409 | DOI: http://dx.doi.org/10.33448/rsd-v10i2.12267

Figura 9. Google Classroom - Chat.

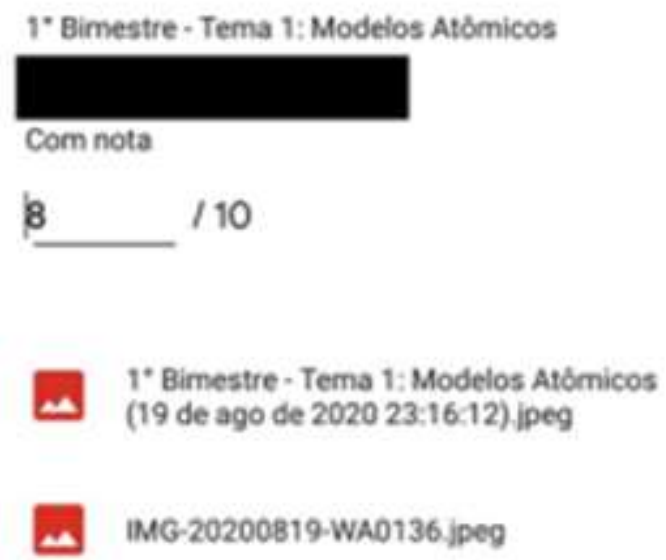

Comentários particulares

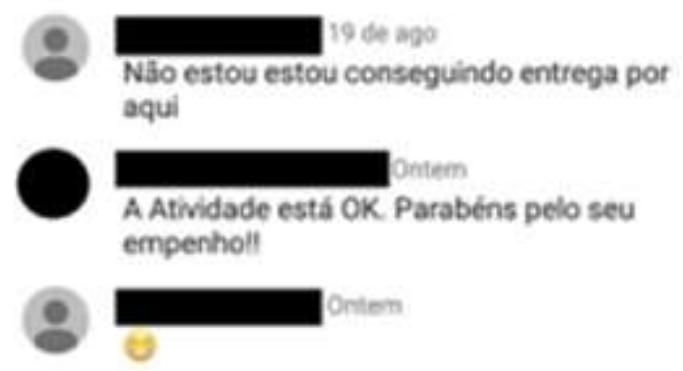

Fonte: Google Classroom

A Figura 9 revela dificuldade de estudante em compreender o funcionamento da plataforma digital.

É importante mencionar que, além das questões relacionadas ao acesso digital, ao uso da plataforma adotada e à comunicação, o enfrentamento à pandemia trouxe desafios pessoais que também dificultaram a participação dos estudantes nas aulas virtuais, como pode ser observado na Figura 10.

Figura 10. Google Classroom - Chat.

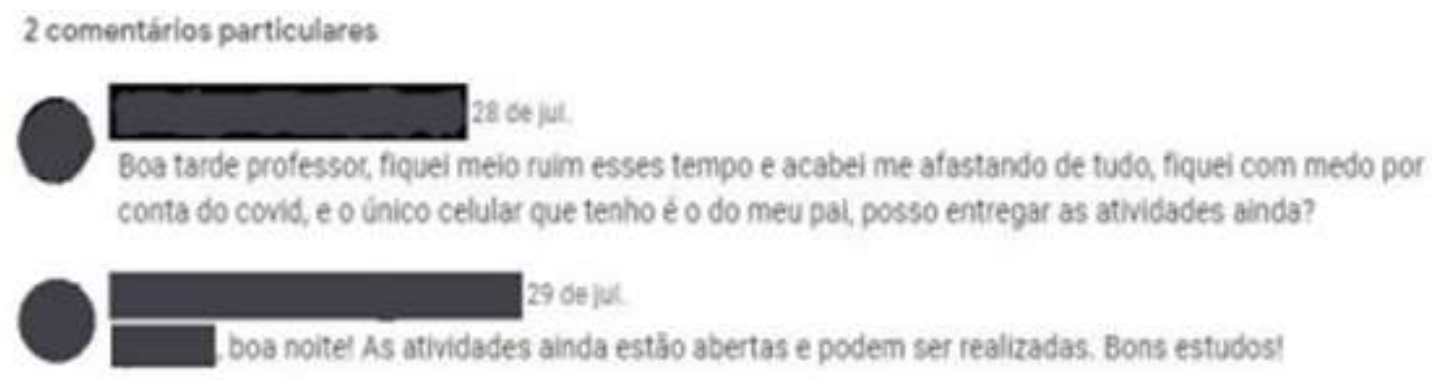

Fonte: Google Classroom.

A Figura 10 apresenta comentário de estudante revelando preocupação com a própria saúde, além da dificuldade de acesso digital decorrente da falta de dispositivo. 
No contexto da pandemia, a atuação docente, por meio de aulas virtuais na rede estadual de ensino de São Paulo, encontra dificuldades semelhantes às que ocorrem no contexto global, conforme dados da ONU.

O Fundo das Nações Unidas para a Infância, Unicef, afirma que a pandemia de COVID-19 gerou uma crise na educação não somente com o fechamento das escolas, mas com a falta de treinamento adequado para ensino a distância por parte dos professores.

Dos 63 milhões de docentes afetados, cerca de 9,1 milhões não receberam qualquer treinamento nessa área e encontram dificuldade para adaptar-se ao novo quadro. Um outro problema é que quase metade dos alunos não têm acesso à internet tornando o ensino a distância um desafio (ONU, 2020).

Nesse panorama, docentes e estudantes enfrentaram o desafio de encontrar novas maneiras de ensinar e aprender. A despeito dos entraves, o uso das ferramentas digitais trouxe alguns ganhos, como a elaboração de novas estratégias didáticas, o estímulo à busca pelo conhecimento e o fortalecimento da autonomia dos estudantes.

\subsection{Relato de prática}

A proposta didática desenvolvida no contexto estudado buscou estimular nos estudantes o olhar investigativo e reflexivo, como preconiza a Base Nacional Comum Curricular.

A abordagem investigativa deve promover o protagonismo dos estudantes na aprendizagem e na aplicação de processos, práticas e procedimentos, a partir dos quais o conhecimento científico e tecnológico é produzido. Nessa etapa da escolarização, ela deve ser desencadeada a partir de desafios e problemas abertos e contextualizados, para estimular a curiosidade e a criatividade na elaboração de procedimentos e na busca de soluções de natureza teórica e/ou experimental (Brasil, 2018 - BNCC, p. 551).

Diante do cenário da pandemia de COVID-19, e considerando as orientações da Secretaria da Educação do Estado de São Paulo para o ensino remoto por meio de ferramentas digitais (São Paulo, 2020d), foram utilizados os recursos que se mostraram mais adequados para ensino e aprendizagem de Química.

Assim, foram propostas atividades que contemplassem o Currículo Paulista, considerando conteúdos disponibilizados no CMSP, com a utilização de outras plataformas digitais, como YouTube, Stoodi, Descomplica, PhetColorado. A expectativa foi oportunizar a interatividade e a reflexão, favorecendo a autonomia dos estudantes no uso de diversos recursos digitais, visando à aprendizagem de Química.

Através da plataforma digital Google Classroom, além das atividades, foi possível enviar informações aos estudantes e seus familiares, viabilizando o diálogo.

Figura 11. Google Classroom - Mural.

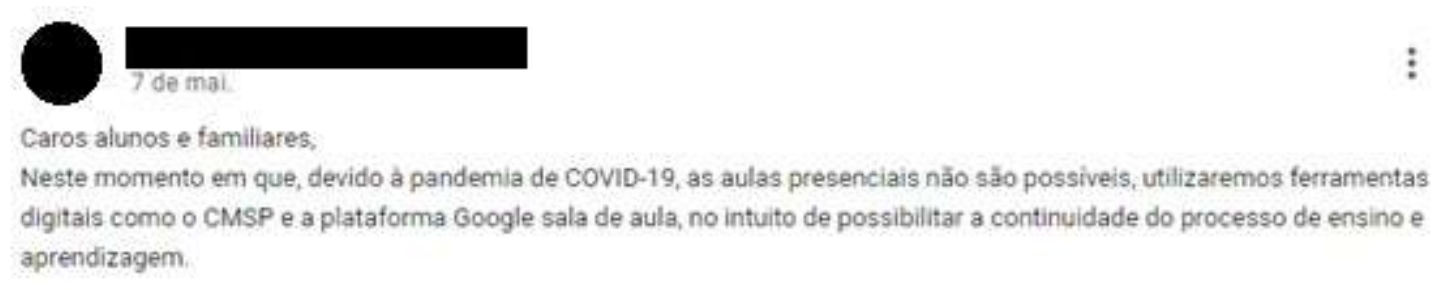

Fonte: Google Classroom

A Figura 11 apresenta contato inicial de docente com a turma através da plataforma digital. 
Além da plataforma digital Google Classroom, foram utilizados outros canais de comunicação com os estudantes, como e-mail, WhatsApp e Facebook. Esses recursos adicionais mostraram-se adequados no sentido de manter o diálogo e contribuir para a superação de dificuldades de acesso, estimulando a participação nas atividades.

Figura 12. Mensagem de estudante via $e$-mail.

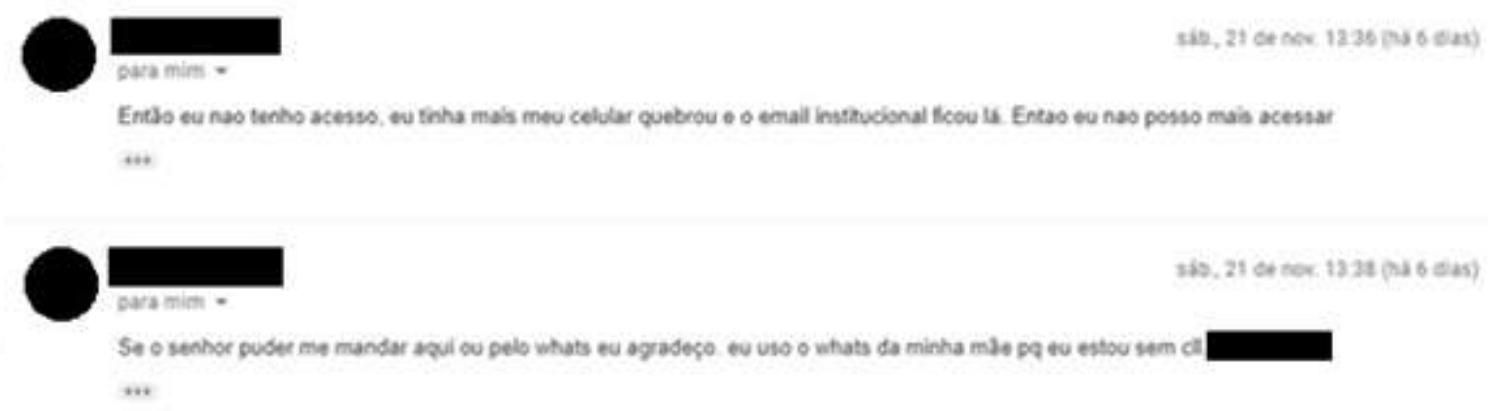

Fonte: Google Gmail

A Figura 12 apresenta mensagem via e-mail em que estudante solicita a utilização do WhatsApp, revelando a necessidade de diversos canais de comunicação.

As atividades postadas na plataforma Google Classroom foram acompanhadas por orientações e links para outros recursos, como arquivos em pdf, formulários Google, conteúdos disponibilizados pelo CMSP, vídeos do YouTube, como pode ser observado nas Figuras 13 e 14.

Figura 13. Google Classroom - Orientação de atividade.

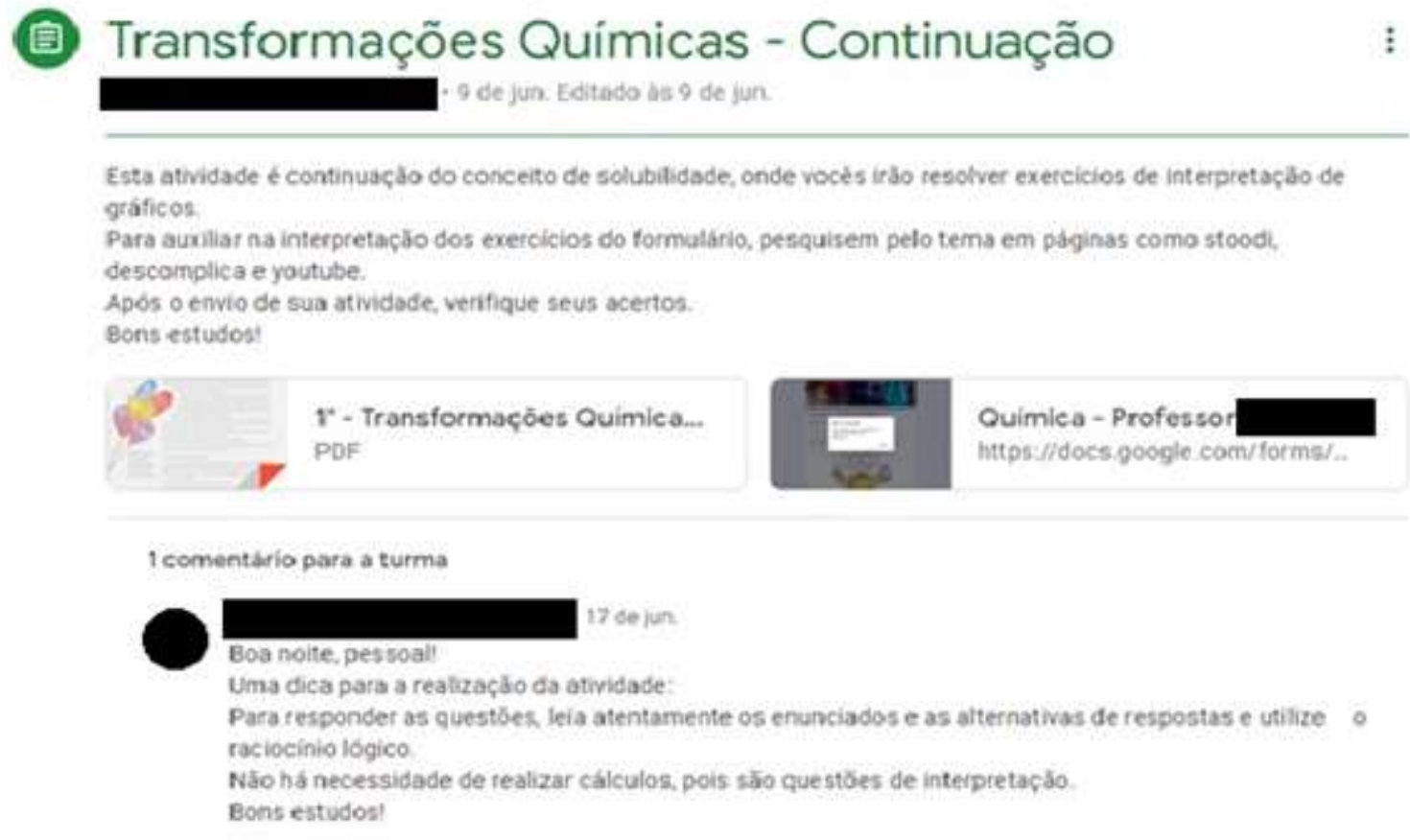

Fonte: Google Classroom.

A Figura 13 apresenta orientação de atividade, proposta na plataforma Google Classroom, com utilização de diversos recursos digitais. 
Figura 14. Google Classroom - Orientação de atividade.

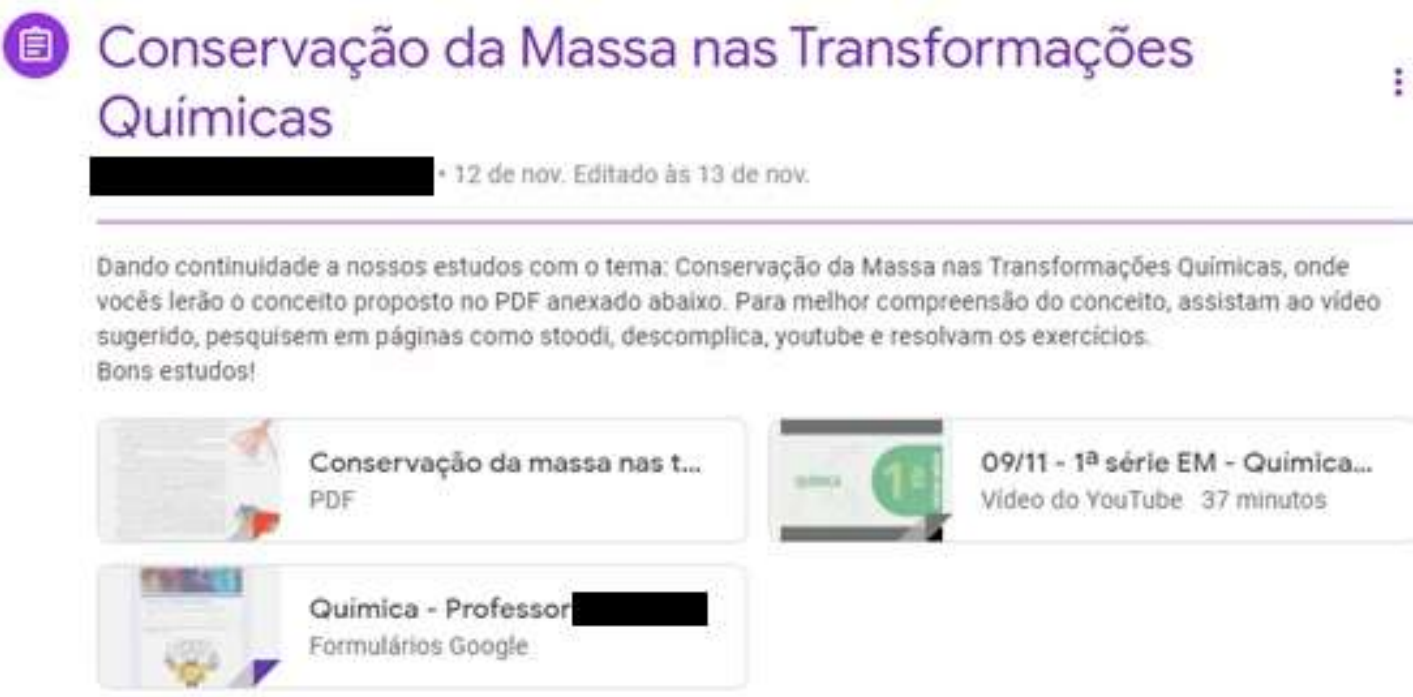

Fonte: Google Classroom.

A Figura 14 apresenta orientação de atividade, proposta na plataforma Google Classroom, com utilização de diversos recursos digitais.

É importante ressaltar que os docentes realizaram devolutivas para todas as postagens dos estudantes, procurando motivá-los e reconhecendo seus esforços, como exemplificado na Figura 15.

Figura 15. Google Classroom - Orientação de atividade.

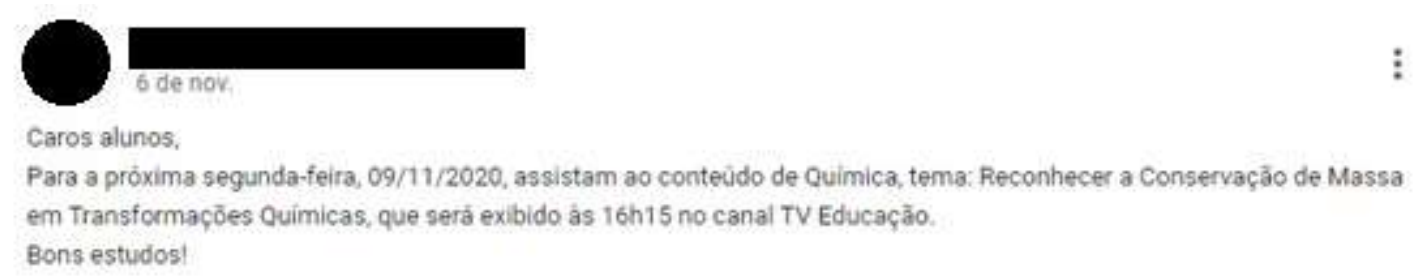

\section{2 comentários para a turma}

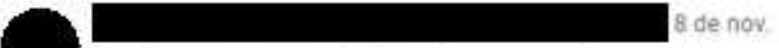

Professor essa aula nẫo vai passar aqui no centro de midias?

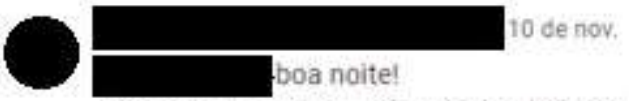

Sim, 0 tema que me refiro dará subsidios para a realização das atividades que, em breve, postarei. Bons estudos!

Fonte: Google Classroom.

A Figura 15 apresenta orientação de atividade, proposta na plataforma Google Classroom, com utilização do CMSP.

Os registros na plataforma Google Classroom indicam que foi possível despertar o interesse dos estudantes pelas atividades de Química, orientar os estudos e elucidar dúvidas, entretanto, parte significativa deles encontrou dificuldades relacionadas ao acesso digital, revelando que esse pode ser o maior desafio para as aulas de Química, como ocorre no ensino remoto de modo geral. 


\section{Considerações Finais}

Devido à suspensão das aulas presenciais, em decorrência da pandemia de COVID-19, a rede estadual de ensino de São Paulo adotou a plataforma digital Google Classroom, aplicativos Google, Centro de Mídias da Educação de São Paulo aplicativo e TV como principais ferramentas para o trabalho docente remoto, na tentativa de garantir aos estudantes a continuidade dos estudos.

A partir de registros realizados por docentes e estudantes na plataforma digital adotada, assim como de informações disponibilizadas publicamente pelo CMSP, além de pesquisa bibliográfica, observou-se que a falta de acesso digital para grande parte dos estudantes é um obstáculo significativo à efetiva garantia da aprendizagem por meio de aulas virtuais, evidenciando que a exclusão digital, que atinge estudantes da rede estadual de ensino de São Paulo, reflete a realidade global, considerando os dados da UNESCO (2020), segundo os quais "mais da metade dos 1,5 bilhão de alunos que estão privados de frequentar as escolas devido à pandemia da COVID-19 não possui computador para acompanhar remotamente as aulas e $43 \%$ não têm acesso à internet"'.

Ademais, observou-se que o trabalho docente remoto teve outros empecilhos, como a necessidade da aquisição autônoma de conhecimentos sobre a funcionalidade das ferramentas, assim como a utilização de dispositivos e redes de internet insuficientes.

Quanto à funcionalidade das ferramentas digitais adotadas, o estudo sugere que atenderam às necessidades emergenciais do ensino remoto, como evidenciado no relato de prática, entretanto, as análises não possibilitam mensurar as implicações na efetiva aprendizagem.

No ensino de Química, percebeu-se que as ferramentas digitais favorecem a pesquisa e o acesso a aplicativos, sites $e$ blogs que tratam de temas de interesse da disciplina, entretanto, as dificuldades referentes ao acesso digital dos estudantes mostraram-se importante obstáculo.

É possível considerar que o uso de ferramentas digitais de ensino e aprendizagem tem aspectos positivos, como possibilitar novas maneiras de ensinar e aprender, favorecendo o uso de diferentes linguagens e a autonomia dos estudantes.

As reflexões deste estudo sugerem que, na Educação Básica, o uso exclusivo de ferramentas digitais pode não ser adequado, porém pode complementar outras estratégias pedagógicas, na perspectiva de que o ensino e a aprendizagem extrapolam os muros escolares, como sugere Moran: "A sala de aula será, cada vez mais, um ponto de partida e de chegada, um espaço importante, mas que combina com outros espaços para ampliar as possibilidades de atividades de aprendizagem" (Moran, 2009, p. 350).

Os desafios educacionais decorrentes da pandemia de COVID-19 revelaram dificuldades e iniciativas institucionais, no sentido de garantir a estudantes e docentes as condições de continuidade do processo de ensino e aprendizagem. Ademais, os docentes desenvolveram diversas habilidades e práticas pedagógicas, rompendo padrões tradicionais. Assim, vislumbra-se a possibilidade de que esse cenário adverso contribua para a construção de novos modelos de educação escolar, que incluam políticas educacionais de inclusão digital, favorecendo o desenvolvimento de estratégias fundamentadas na diversidade de tempos, espaços e linguagens.

Este estudo não possibilita avaliar as consequências do ensino remoto para a efetiva aprendizagem, indicando a necessidade de outros trabalhos nesse sentido.

\section{Referências}

Secretaria da Educação do Estado de São Paulo. EFAPE - Escola de Formação de Profissionais da Educação. Currículo Paulista. 2020f. https://efape.educacao.sp.gov.br/curriculopaulista/wp content/uploads/sites/7/2019/09/curriculo-paulista-26-07.pdf

Centro de Mídias da Educação de São Paulo - CMSP. Página oficial no Facebook.2020g. https://www.facebook.com/centrodemidiasp

Centro de Mídias da Educação de São Paulo - CMSP. Página oficial no Instagram.2020h. https://www.instagram.com/centrodemidiasp/?hl=pt-br 
Decreto Legislativo $\mathrm{n}^{\circ}$ 06/2020. Reconhece, para os fins do art. 65 da Lei Complementar $\mathrm{n}^{\circ}$ 101, de 4 de maio de 2000, a ocorrência do estado de calamidade pública, nos termos da solicitação do Presidente da República encaminhada por meio da Mensagem no 93, de 18 de março de $2020.2020 \mathrm{~b}$. http://www.in.gov.br/en/web/dou/-/decreto-legislativo 249090982

Decreto $N^{\circ}$ 64.881, de 22 de março de 2020. Decreta quarentena no Estado de São Paulo, no contexto da pandemia do COVID-19 (Novo Coronavírus), e dá providências complementares. 2020c. https://www.saopaulo.sp.gov.br/wp-content/uploads/2020/03/decreto quarentena.pdf>

Decreto ${ }^{\circ}$ 64862, de 13/03/2020. Dispõe sobre a adoção, no âmbito da Administração Pública direta e indireta, de medidas temporárias e emergenciais de prevenção de contágio pelo COVID-19 (Novo Coronavírus). 2020a. https://www.saopaulo.sp.gov.br/wp-content/uploads/2020/03/decreto-64862.pdf

Decreto ${ }^{\circ}$ 64879, de 20/03/2020. Reconhece o estado de calamidade pública, decorrente da pandemia do COVID-19, que atinge o Estado de São Paulo, e dá providências correlatas. 2020b. https://www.saopaulo.sp.gov.br/wp-content/uploads/2020/03/decretos-64879-e 64880.pdf

El Páis. O mapa do coronavírus: como aumentam os casos dia a dia no Brasil e no mundo. https://brasil.elpais.com/brasil/2020/03/12/ciencia/1584026924_318538.html

Flick, U (2009). Desenho da pesquisa qualitativa: Artmed.

Freire, P. (1996). Pedagogia da autonomia: saberes necessários à prática educativa: Paz e Terra.

Fundação Oswaldo Cruz - Fiocruz. Quais as diferenças entre isolamento horizontal, vertical e lockdown. 2020g. portal.fiocruz.br

Gil, A. C. (2019). Métodos e técnicas de pesquisa social (7a ed.): Atlas.

Köche, J. C. (2011). Fundamentos de metodologia científica: Vozes. http://www.brunovivas.com/wp-content/uploads/sites/10/2018/07/K\%C3\%B6cheJos\%C3\%A9-Carlos0D0AFundamentos-de-metodologia-cient\%C3\%ADfica-_-teoria-da0D0Aci\%C3\%AAncia-e-inicia\%C3\%A7\%C3\%A3o-\%C3\%A0pesquisa.pdf

Lei n. 9.394, de 20 de dezembro de 1996. Lei de Diretrizes e Bases da Educação Nacional. http://www.planalto.gov.br/ccivil_03/leis/19394.htm

Lei $\mathrm{n}^{\circ}$ 13.979, de 06 de fevereiro de 2020. Dispõe sobre as medidas para enfrentamento da emergência de saúde pública de importância internacional decorrente do coronavírus responsável pelo surto de COVID 2019. 2020c. http://www.in.gov.br/en/web/dou/-/lei-n-13.979-de 6-de-fevereiro-de-2020-242078735

Ludke, M., \& André, M. E. D. A. (2013). Pesquisas em educação: uma abordagem qualitativa: E.P.U.

MEC. Base Nacional Comum Curricular - BNCC. http://basenacionalcomum.mec.gov.br/images/BNCC_EI_EF_110518_versão final_site.pdf

Medida Provisória n ${ }^{\circ}$ 934, de 01 de abril de 2020. Estabelece normas excepcionais sobre o ano letivo da educação básica e do ensino superior decorrentes das medidas para enfrentamento da situação de emergência de saúde pública de que trata a Lei $\mathrm{n}^{\circ} 13.979$, de 6 de fevereiro de 2020 . 2020d. http://www.in.gov.br/en/web/dou/-/medida-provisoria-n-934-de-1-de-abril-de 2020-250710591

Ministério da Educação. Base Nacional Comum Curricular. 2018. http://basenacionalcomum.mec.gov.br/

Ministério da Educação. Parecer CNE 05/2020, de 28 de abril de 2020. 2020a. https://www.semesp.org.br/legislacao/parecer cne-cp-no-5-2020/

Ministério da Saúde. Portaria nº 188, de 3 de fevereiro de 2020. 2020e. http://www.in.gov.br/web/dou/-/portaria-n-188-de-3-de fevereiro-de-2020-241408388

Moran, J. M., Masetto, M. T., \& Behrens, M. A.(2006). Novas tecnologias e mediação pedagógica. (10a ed.): Papirus

Moran, José Manuel (2009). A contribuição das tecnologias para uma educação inovadora. Revista Contrapontos, Itajaí, 4(2), 347-356, maio/ago. https://edumidiascomunidadesurda.files.wordpress.com/2016/05/josc3a9- manuel-moran-a-contribuic3a7c3a3o-das-tecnologias-para-uma educac3a7c3a3oinovadora.pdf

$O N U$. Organização das Nações Unidas. Mais de 9 milhões de professores sem treinamento profissional durante a pandemia. 2020. https://news.un.org/pt/story/2020/06/1715482

OPAS. Organização Pan-americana de Saúde. Folha informativa - COVID-19 (doença causada pelo novo coronavírus). 2020a. https://www.paho.org/bra/index.php?option=com_content\&view=article\&id=610 1:covid19\&Itemid=875

OPAS. Organização Pan-americana de Saúde. OPAS disponibiliza em português novo guia da OMS sobre máscaras cirúrgicas e de tecido. 2020 b. https://www.paho.org/bra/index.php?option=com_content\&view=article\&id=619 4:opas-disponibiliza-em-portugues-novo-guia-da-oms-sobre-mascaras cirurgicas-e-de-tecido $\&$ Itemid $=812$

Parecer CNE 15/2020, de 06 de outubro de 2020. 2020f. http://portal.mec.gov.br/index.php?option=com_docman\&view=download\&alias=160391-pcp01520\&category_slug=outubro-2020-pdf\&Itemid=30192

Paulleti, F., Mendes, M., Rosa, M. P. A., \& Catelli, F. (2017). Ensino de Química mediado por tecnologias digitais: o que pensam os professores brasileiros? Revista Interacções, Portugal, 44, 144-167

Pereira, A. S. et al (2018). Metodologia da pesquisa científica. UAB/NTE/UFSM. https://www.ufsm.br/app/uploads/sites/358/2019/02/Metodologia-daPesquisa-Cientifica_final.pdf

Secretaria da Educação do Estado de São Paulo - SEDUC. Documento orientador - aulas não presenciais. Abril/2020. 2020d. http://www.escoladeformacao.sp.gov.br/portais/Portals/84/docs/pdf/documento orientador-atividades-escolares-nao-presenciais.pdf 
Research, Society and Development, v. 10, n. 2, e8710212267, 2021

(CC BY 4.0) | ISSN 2525-3409 | DOI: http://dx.doi.org/10.33448/rsd-v10i2.12267

Secretaria da Educação do Estado de São Paulo $\quad-\quad$ SEDUC. $\quad$ Resolução $\mathrm{n}^{\circ} \quad 44, \quad$ de $20 / 04 / 2020 . \quad 2020$. http://www.educacao.sp.gov.br/lise/sislegis/detresol.asp?strAto=202004204400

UNESCO. A exclusão digital no ensino à distância é motivo de preocupação da UNESCO neste decurso da Pandemia COVID-19. https://cvunesco.org/10cnu/405-a-exclusao-digital-no-ensino-a-distancia-e-motivo-de preocupacao-da-unesco-neste-decurso-da-pandemia-covid-19?start=5 